Удк 321.01

DOI 10.24147/2542-1514.2020.4(1).14-20

(cC) BY 4.0

НАЧАЛО МАСШТАБНОЙ ПОЛИТИЧЕСКОЙ РЕФОРМЫ В РОССИИ: НОВЫЙ ПОВОРОТ В 2020 г.

\title{
И.А. Ветренко
}

Северо-Западный институт управления Российской академии народного хозяйства и государственной службы при Президенте Российской Федерации, г. Санкт-Петербург, Россия

\author{
Информация о статье \\ Дата поступления - \\ 25 января 2020 г. \\ Дата принятия в печать - \\ 19 марта 2020 г. \\ Дата онлайн-размещения - \\ 30 марта 2020 г. \\ Ключевые слова \\ Политическая реформа, \\ политические изменения, \\ парламентская республика, \\ смешанная республика, \\ институализация, Конституция, \\ конституционная реформа
}

\begin{abstract}
Анализируются политические нововведения, которые были озвучены в Послании Президента РФ 15 января 2020 г. Выделяются причины предстоящих реформ и дается прогноз по их реализации. Данные изменения связываются с предстоящим процессом передачи власти после 2024 г. Объясняются позитивные и негативные последствия усиления позиций парламента в стране, наделения особыми полномочиями Государственного Совета как института власти. Анализируются изменения, которые планируется внести в Конституцию РФ.
\end{abstract}

\section{THE BEGINNING OF A LARGE-SCALE POLITICAL REFORM IN RUSSIA: A NEW TURN IN 2020}

\section{Inna A. Vetrenko}

North-west institute of management of Russian Presidential Academy of National Economy and Public Administration (RANEPA), St. Petersburg, Russia

\author{
Article info \\ Received - \\ 2020 January 25 \\ Accepted - \\ 2020 March 19 \\ Available online - \\ 2020 March 30
}

\section{Keywords}

Political reform, political change, parliamentary republic, mixed republic, institutionalization, Constitution, constitutional reform
The subject. The article is devoted to the analysis of the draft political and constitutional reform that was announced in the last Presidential Address to the Federal Assembly at January 15, 2020.

The purpose of the article is to try to predict the positive and negative consequences of changing the legal status of the highest Russian authorities.

The methodology of the study includes analysis and interpretation of Presidential Addresses to the Federal Assembly and Russian Constitution as well as dialectical approach and methods of political science.

The main results and scope of their application. For a long time there was a clear request for changes in the government, and various expert platforms discussed issues related to changing the Constitution of the Russian Federation, which was adopted at a national referendum in December 1993.

On January 15, 2020, Vladimir Putin addressed his 16th message to the Parliament. In accordance with the Constitution, the President of Russia annually addresses the Federal Assembly with a message on the situation in the country and on the main directions of domestic and foreign policy. The last address turned out to be a landmark and historical one, as it announced the main provisions of the upcoming large-scale political and constitutional reform in Russia. Heads of constituent entities, members of the State Duma and the Federation Council, Prime Minister and Deputy Prime Ministers, Federal Ministers, heads of Fed- 
eral bodies, judges will no longer be able to have foreign citizenship or a foreign residence permit. He proposed even more stringent requirements for a candidate for the post of President: no foreign citizenship or residence permit even in the past, as well as permanent residence in Russia for at least 25 years. The position of the State Council is being strengthened and it is reflected in the Constitution of the Russian Federation as an institution of power in the country. The position of the Federal Assembly is strengthened by the fact that the Parliament is given the right to approve the candidacy of the Prime Minister, as well as all Deputy Prime Ministers and Federal Ministers. The status of local self-government and the role of governors in the regions is being raised.

The main reason for the reform is the desire to reduce the powers of the President and transfer part of them to the Parliament, so that the next President is no longer endowed with virtually absolute power, and, in turn, can not initiate another reform without the approval of all branches of government.

The author of the article identifies the reasons for the political reform and gives forecasts for the future after its implementation.

Conclusions. The author links these changes to the upcoming transfer of presidential power after 2024. The reform does not mean the transition of the Russian Federation to a parliamentary republic, since the head of state retains the status of a key figure in the political system, and it is he who has concentrated key functions. Fixing a number of social obligations in the Constitution in terms of salaries and pensions will not have a significant impact on the socio-economic situation.

\section{1. Введение. Перманентные политические из- менения в стране}

Современная Россия перманентно живет в состоянии политических перемен и реформ. Административная, налоговая, таможенная, пенсионная реформы - это далеко неполный список значительных государственных изменений, которые мы пережили за последнее время. Как известно, основная цель любой политической реформы: укрепление вертикали власти для сохранения территориальной целостности страны, проведения централизованной единой политики по борьбе с различными угрозами, в том числе и с терроризмом [1-4]. Как правило, все преобразования связаны с вопросами безопасности, политической стабильности, сохранения и создания дополнительных гарантий политического единства страны. Однако несменяемость власти в нашей стране за последние 20 лет создала ощущение стагнации в области политики.

Сколько раз мы задавали себе вопрос: «Когда в политике нашей страны произойдут хоть какие-нибудь изменения? Как долго во главе нашего государства будет оставаться Владимир Путин?». И вот наступило это долгожданное время прозрений, кое-что стало понятно, более того начались такие изменения, к которым многие оказались не готовы, а некоторые вообще не понимают, что происходит в стране.

В соответствии с Конституцией, президент России ежегодно обращается к Федеральному Собранию с посланием о положении в стране и об основных направлениях внутренней и внешней политики.
Согласно традиции, на оглашении послания присутствуют депутаты обеих палат Федерального Собрания и приглашенные. В Кремль приглашают членов правительства, председателей Конституционного и Верховного судов, генпрокурора, председателя Центризбиркома, главу Счетной палаты, членов Государственного Совета, глав основных конфессий и представителей Общественной палаты России.

Следует отметить, что начиная с 2008 года, послание представлялось в конце года, в ноябре или декабре, что логично, исходя из природы этого документа. Он является политико-правовым, отражает видение президентом стратегических направлений развития страны на ближайшую перспективу, как правило, на очередной год. Включает в себя как положения политического, экономического, идеологического характера, так и конкретные предложения, касающиеся законотворческой работы парламента [5, с. 121; 6-8]. Последнее послание перенесли на начало года, что само по себе вызвало у экспертного сообщества некоторые подозрения о назревающих политических переменах глобального характера.

\section{2. Время политических перемен}

15 января 2020 года Президент нашей страны обратился к Федеральному Собранию с ежегодным посланием. Первый час послания для многих присутствующих в зале вызывал даже ощущение дежавю, только цифры по социальной политике и социальным выплатам звучали очень конкретные, чего раньше не было, создавалась иллюзия некой «дороговизны» послания Президента этого года. Впослед- 
ствии глава Счетной палаты Алексей Кудрин так и оценил 16-е послание российского президента Владимира Путина Федеральному Собранию, как «самое дорогое» на его памяти, по его подсчётам, озвученные президентом меры потребуют от 400 до 500 млрд руб. в год ${ }^{1}$. Они должны пойти на то, чтобы минимальный размер оплаты труда не был ниже прожиточного минимума трудоспособного населения, на достойное пенсионное обеспечение и индексацию пенсий, на увеличение материнского капитала и введение его выплаты на первого ребенка.

А далее началось самое интересное, то, о чем долго говорили и даже мечтали - внесение изменений в Конституцию РФ - в одночасье стало реальностью. Из уст Президента прозвучал целый пакет предложений о поправках в Основной закон нашего государства. После их внесения главы субъектов, члены Государственной Думы и Совета Федерации, премьер-министр и вице-премьеры, федеральные министры, руководители федеральных органов, судьи больше не смогут иметь иностранное гражданство или иностранный вид на жительство. Еще более жесткие требования он предложил предъявлять к претенденту на пост президента: отсутствие иностранного гражданства или вида на жительство даже в прошлом, а также постоянное проживание в России не менее 25 лет. На первый взгляд, это замечательное требование к кандидатам, которое сделает будущего президента настоящим безукоризненным гражданином страны, однако при более внимательном анализе оно ограничивает права жителей наших возвращенных территорий - Крыма и Севастополя, ни один из которых при всем желании Президентом РФ стать не сможет.

Но главное заключается в том, что это послание запускает политическую реформу в стране. Владимир Путин, который с первых дней его прихода к власти укреплял властную вертикаль, усиливал роль и значимость президента, уводя нас от парламентской республики в сторону президентской, вдруг предложил доверить Государственной Думе не просто согласование, как сейчас, а утверждение кандидатуры председателя правительства. После этого, по его представлению, Дума должна утверждать всех вице-премьеров и ряд федеральных министров. А президенту будет вменена обязанность назначить их

\footnotetext{
${ }^{1}$ Кудрин назвал послание Путина «самым дорогим» на его памяти. URL: https://www.rbc.ru/rbcfreenews/5e1f0e3e9a 7947d0cabe6467https://www.rbc.ru/rbcfreenews/5e1f0e3e 9a7947d0cabe6467 (дата обращения: 15.01.2020).
}

на должность. При этом президент, по предложению В.В. Путина, сохраняет прямое руководство вооруженными силами и правоохранительной системой. Он может назначать руководителей силовых ведомств. Но при этом предлагается смягчающая оговорка - по итогам консультаций с Советом Федерации. Такой же принцип В.В. Путин предложил и при назначении прокуроров регионов. “Сегодня они назначаются по согласованию с региональным законодательным собранием... Это может на практике приводить к неформальным обязательствам перед местными властями», - пояснил президент ${ }^{2}$.

\section{3. Причины политических реформ}

Политические реформы, который проводил Владимир Путин с 2000 г., были понятны, они направлены на укрепление вертикали власти в стране. В рамках этих реформ произошли следующие основные преобразования:

1. Создание 7 федеральных округов, оказавшихся промежуточным и, одновременно, связующим звеном между центром и регионами России. Были образованы Центральный, Северо-Западный, СевероКавказский, Приволжский, Уральский, Сибирский, Дальневосточный федеральные округа. Задача - привести действия и постановления региональных властей в соответствие с общефедеральными законодательством и политикой [9; 10]. Введение полномочных представителей в Совет безопасности РФ возвысило их над всеми губернаторами и над большинством федеральных министров и законодателей.

2. С целью укрепления позиций федеральной власти и снижения была произведена реорганизация Совета Федерации, которая также серьезно ущемила статус региональных лидеров. С 1996 года главы субъектов РФ и председатели региональных парламентов являлись членами верхней палаты (сенаторами). Вместо них сенаторами становились рядовые представители региональных исполнительных и законодательных органов (по 2 от каждого субъекта РФ) [11]. В результате уменьшались как возможности влияния региональных лидеров на центральную власть, так и политический вес самих регионов.

3. Создан Государственный совет РФ - совещательный орган при Президенте, рассматривающий насущные вопросы жизни страны. В Госсовет вошли главы субъектов федерации. Он не является органом

2 Послание Президента Федеральному Собранию. URL: http://www.kremlin.ru/events/president/news/62582 (дата обращения: 21.01.2020). 
государственной власти, поскольку не обладает властными полномочиями [12].

Построение административной вертикали привело к установлению более развитого и акцентированного политического и экономического контроля федерального центра над регионами [13]. Еще одной характерной чертой этого процесса стало увеличение полномочий исполнительных органов власти и снижение роли представительных органов как на федеральном, так и на региональном уровня ${ }^{3}$.

Масштабная политическая реформа 2020 г. заставила задаться вопросом, почему Владимир Путин вдруг пошел на сокращение властных полномочий Президента и усиление положения парламента в стране? Причины этого стали понятны, и даже очевидны, чуть позже, когда президент затронул Государственный Совет. Многие граждане нашей страны впервые услышали о таком существующем у нас институте власти, и это понятно. Дело в том, что о данном органе власти нет ни слова в Конституции, хотя фактически он существует! В экспертной среде его именуют параконституциональным институтом, наряду с Общественной палатой, институтом полномочных представителей Президента РФ в федеральных округах, о которых тоже нет ни слова в главном законе страны. Напомню, Государственный совет России образован 1 сентября 2000 года в соответствии с Указом Президента Российской Федерации В. В. Путина и по его же инициативе. Согласно положению о нем Госсовет является совещательным органом, содействующим реализации полномочий главы государства по вопросам обеспечения согласованного функционирования и взаимодействия органов государственной власти; в него входят главы субъектов федерации, а первое его заседание состоялось уже 22 ноября 2000 года. Мало кто о нем в нашей стране до 15 января 2020 года слышал, а еще меньше понимал, что это за инструмент власти и какое его назначение. Президент же в послании Федеральному Собранию предложил расширить и укрепить полномочия Государственного Совета и внести в Конституцию норму о его статусе при рассмотрении наиболее значимых для граждан и страны вопросов.

После этого экспертному сообществу стало окончательно понятно, что Владимир Путин собирается покинуть вершину политического Олимпа

\footnotetext{
3 Вертикаль власти: реформы российской политической системы 2000-х гr. URL: http://rusrand.ru/analytics/vertikalvlasti-reformy-rossiyskoy-politicheskoy-sistemy-2000-gg (дата обращения: 30.01.2020).
}

нашей страны, уступив её следующему кандидату, но при этом демонтировать и забрать с собой эту самую вершину, чтобы установить в другом месте. Желание сократить полномочия президента и передать их часть парламенту, очевидно, вызвано тем, чтобы следующий президент уже не был наделён фактически абсолютной властью, и уже сам, в свою очередь, не мог провести очередную реформу управления без согласования со всеми ветвями власти. Тем самым действующий президент хочет сохранить возможность влиять на принятие решений в стране, для чего легализует и укрепляет властными полномочиями Госсовет и должность его председателя. Видимо, готовит «плацдарм» для себя, иначе это не объяснить с позиций логики.

\section{4. Легитимация политической реформы}

В.В. Путин предложил провести всенародное голосование по пакету предложенных изменений в Конституцию. Его дата пока неизвестна, но из последовавших почти сразу заявлений главы ЦИК Эллы Памфиловой, стало понятно, что это может произойти раньше единого дня голосования, который в этом году будет приходиться на 13 сентября 4 .

Само по себе увеличение значимости парламента в нашей стране - решение разумное. Это приведет к балансу всех ветвей власти, повысит значимость парламентариев, но не настолько сильно, как это требуется. На самом деле то, что предложил президент, это лишь незначительные поправки. Если бы Государственная Дума могла своим большинством выдвигать кандидатуру на пост председателя, то это было бы весомо, а в предлагаемой редакции изменения носят, в большей степени, имитационный характер.

Однако историчность и новый политический акцент этому посланию придала третья его часть, которая касалась внешнеполитических вопросов. В.В. Путин констатировал, что требования международного законодательства, решения международных органов могут действовать на территории России только в той части, в которой они не влекут за собой ограничения прав и свобод граждан РФ и не противоречат Конституции страны.

В нашей стране внешняя политика всегда определяла внутреннюю, а это историческое заявление расставляет приоритеты в обратном порядке. Смело,

4 Голосование по поправкам в Конституцию может проводиться в будний день. URL: https://www.ntv.ru/novosti/ 2281945/ (дата обращения: 24.01.2020). 
а главное, правильно, но несколько запоздало. Эта мера назрела еще лет 15 назад [14].

Послание стало месседжем, за которым последовали незамедлительное реальное политическое «цунами»: отставка Правительства РФ, которую, как оказалось, никто не ожидал, хотя определённые предвестники, безусловно, были. Послание, начиная с 2008 года оглашалось в конце года (ноябрь, декабрь), поскольку оно закладывает основные векторы дальнейшего развития в стране на следующий год, в этот раз его перенесли на январь, видимо, в связи с особой значимостью его, которая требовала дополнительной подготовки, а вернее, проработки последующей за ним через 15 минут отставки всего кабинета министров вместе с его председателем Дмитрием Медведевым. К тому же, все последние отчеты Правительства демонстрировали его неэффективность. Вначале пенсионная реформа, инициированная правительством Медведева, сделала его одним из самых непопулярных в новейшей истории, после чего в экспертной среде за этим правительством закрепился ярлык «антисоциальное». Затем заместитель председателя Правительства РФ Татьяна Голикова открыто призналась в провале реформы здравоохранения, а цифры по демографии наглядно продемонстрировали нам нарастающий кризис и стали, фактически, контрольным выстрелом. Всем стало ясно, что правительство перешло в состояние «сакральной жертвы», и «жертвоприношение» состоялось 5 !

Последовавшие за посланием процессы идут с такой скоростью, что даже самые политизированные граждане не успевают их отслеживать. На следующий день после послания стала известна фигура нового председателя правительства, одобренная Государственной Думой, создана и приступила к своим непосредственным обязанностям рабочая группа по подготовке пакета изменений в Конституцию, полным ходом идет процесс подготовки к голосованию. Стремительно было сформировано новое правительство, в котором 12 министров сохранили свои посты, а 8 назначены вновь. Остались в составе фигуры, которые непопулярны у населения страны, а новые, хоть и не имеют антирейтинга, но и политического веса у них нет никакого. Однако никто не отменял политические технологии, с помощью которых в кратчайшие сроки можно создать рейтинг новому правительству [15]. Создается ощущение, что в России объявлена всеобщая политическая мобилизация, и текущий месяц рискует войти в историю нашей страны, как самый насыщенный политическими переменами исторически значимыми событиями.

\section{5. Выводы}

Сегодня все обсуждают вопрос: как новые поправки к Конституции повлияют на политический и конституционный строй в нашей стране. Позволим и мы сделать некоторые прогнозы со ссылкой на экспертное мнение. Принимаемые поправки призваны сделать политическую систему РФ более сбалансированной, с четко дифференцированной системой сдержек и противовесов между ветвями и уровнями власти. Отдельного внимания заслуживает именно усиление роли регионов через повышение значимости института губернатора. Это идет в противовес с ранее доминировавшей тенденцией централизации власти. Важное значение имеет усиление законодательной ветви власти через передачу Государственной Думе отдельных полномочий по утверждению Правительства. Но это не означает перехода РФ к парламентской республике, так как глава государства сохраняет за собой статус ключевой фигуры в политической системе, и именно у него сконцентрированы ключевые функции 6 . Что касается закрепления ряда социальных обязательств в Конституции в части зарплат и пенсий, то они не окажут существенного влияния на социально-экономическую ситуацию, так как эти нормы и в текущий момент находятся в рамках федеральных законов. Очень хочется надеяться, что данные изменения не носят характер популистических, а создадут реальные социальные гарантии гражданам нашей страны [16].

\section{СПИСОК ЛИТЕРАТУРЫ}

1. Боброва Н.А. Итоги муниципальной реформы - 2014 / Н.А. Боброва // Муниципальная служба: правовые вопросы. - 2018. - № 1. - С. 27-31.

\footnotetext{
5 Голикова признала неудачной оптимизацию здравоохранения в регионах. URL: https://www.rbc.ru/society/03/11/ 2019/5dbecba99a79470b57a29e69 (дата обращения: 22.01.2020).
}

${ }^{6}$ Изменение Конституции в 2020 году: 10 поправок, предложенных Президентом РФ. URL: https://zakonguru.com/ izmeneniya/konstitutsia-rf.html (дата обращения: 07.02.2020). 
2. Петров С.М. К вопросу о правовом регулировании разграничения компетенции между уровнями публичной власти в России / С.М. Петров // Новый юридический журнал. - 2012. - № 4. - С. 90-96.

3. Кондрашев А.А. Особенности современного формирования политической системы России в контексте характеристики государственного режима / А.А. Кондрашев // Конституционное и муниципальное право. 2012. - № 5. С. 21-32.

4. Воронов А.М. К вопросу о модернизации концепции административного права современной России / А.М. Воронов // Административное право и процесс. - 2017. - № 5. - С. 14-17.

5. Горынина А.В. Постсоветская Россия: опыт обретения нового смысла исторического существования (на основе анализа ежегодных посланий Президента РФ Федеральному Собранию) / А.В. Горынина, А.Х. Хазиев // Ученые записки Казанского университета. - 2007. - Т. 149, кн. 5. - С. 118-129.

6. Зорькин В.Е. Ежегодные Послания Федеральному Собранию Российской Федерации как средство формирования и реализации правовой политики Президента Российской Федерации: автореф. дис. ... канд. юрид. наук / В.Е. Зорькин. - СПб., 2011. - 29 с.

7. Гайдарбекова А.М. Место и роль посланий Президента РФ в политико-правовой жизни общества / А.М. Гайдарбекова // Конституционное и муниципальное право. - 2011. - № 6. - С. 35-37.

8. Тихон Е.А. Послания Президента РФ Федеральному Собранию как политико-правовой акт, определяющий стратегию России в области прав человека / Е.А. Тихон // Конституционное и муниципальное право. 2007. - № 16. - С. 34-40.

9. Нарутто С.В. Конституция, федерализм и единство государственно-правовой системы России / C.B. Нарутто // Lex Russica. - 2018. - № 11. - C. 83-92. - DOI: 10.17803/1729-5920.2018.144.11.083-092.

10. Коврякова Е.В. Концепции представительных систем и их практическое воплощение в государственном механизме / Е.B. Коврякова // Lex Russica. - 2016. - № 11. - C. 77-90.

11. Колюшин Е.И. Пути реформирования Совета Федерации Федерального Собрания РФ / Е.И. Колюшин // Конституционное и муниципальное право. - 2006. - № 4. - С. 7-14.

12. Гончаров В.В. Роль и место Государственного совета Российской Федерации и полномочных представителей Президента России в федеральных округах в координации системы исполнительной власти в стране и преодолении центробежных политических тенденций / В.В. Гончаров // Юридический мир. - 2008. № 3. - С. 23-28.

13. Гороховатский С.М. Конституционно-правовое регулирование процесса формирования и развития федеративных отношений в России после 2000 г. / С.М. Гороховатский // Актуальные проблемы российского права. - 2015. - № 9. - С. 39-43.

14. Андреева И.Е. Становление и развитие института президентства в РФ / И.Е. Андреева // Армия и общество. - 2013. - № 2. - С. 112-119.

15. Ветренко И.А. Политические технологии в современных политических процессах в России / И.А. Ветренко // Известия Российского государственного педагогического университета им. А.И. Герцена. - 2009. № 4. - С. 21-30.

16. Ветренко И.А. Новые формы популизма в современном мире / И.А. Ветренко // Политика развития, государство и мировой порядок: материалы Всероссийского конгресса политологов. - М.: МГУ, 2018. - С. $109-111$.

\section{REFERENCES}

1. Bobrova N.A. Results of municipal reform-2014. Munitsipal'naya sluzhba: pravovye voprosy = Municipal service: legal issues, 2018, no. 1, pp. 27-31.

2. Petrov S.M. On the issue of legal regulation of the division of competence between the levels of public power in Russia. Novyi yuridicheskii zhurnal = New legal journal, 2012, no 4, pp. 90-96.

3. Kondrashev A.A. Features of the modern formation of the Russian political system in the context of the characteristics of the state regime. Konstitutsionnoe i munitsipal'noe pravo = Constitutional and municipal law, 2012, no. 5, pp. 21-32.

4. Voronov A.M. To the question on the modernization of the concept of administrative law in modern Russia. Administrativnoe pravo i protsess = Administrative law and process, 2017, no. 5, pp. 14-17. 
5. Gorynina A.V., Khaziev A.H. Post-Soviet Russia: the experience of finding a new meaning of historical existence (based on the analysis of the annual messages of the President of the Russian Federation to the Federal Assembly). Uchenye zapiski Kazanskogo universiteta = Scientific notes of Kazan University, 2007, vol. 149, no.5, pp. 118-129.

6. Zorkin V.E. Annual Messages to the Federal Assembly of the Russian Federation as a means of forming and implementing the legal policy of the President of the Russian Federation. Cand. Diss. Thesis. Saint-Petersburg, 2011. 29 p.

7. Gaidarbekova A.M. The place and role of presidential addresses in the political and legal life of society. Konstitutsionnoe i munitsipal'noe pravo = Constitutional and municipal law, 2011, no 6, pp. 35-37.

8. Tikhon E.A. Addresses of the President of the Russian Federation to the Federal Assembly as a political and legal act that determines Russia's strategy in the field of human rights. Konstitutsionnoe $i$ munitsipal'noe pravo $=$ Constitutional and municipal law, 2007, no. 16, pp. 34-40.

9. Narutto S.V. Constitution, federalism and unity of the state-legal system of Russia. Lex Russica, 2018, no 11, pp. 83-92. DOI: 10.17803/1729-5920.2018.144.11.083-092

10. Kovryakova E.V. Concepts of representative systems and their practical implementation in the state mechanism. Lex Russica, 2016, no. 11, pp. 77-90.

11. Kolyushin E.I. Ways of reforming the Federation Council of the Federal Assembly of the Russian Federation. Konstitutsionnoe $\mathrm{i}$ munitsipal'noe pravo = Constitutional and municipal law, 2006, no. 4, pp. 7-14.

12. Goncharov V.V. Role and place of the State Council of the Russian Federation and Plenipotentiary representatives of the President of Russia in Federal districts in coordinating the system of executive power in the country and overcoming centrifugal political trends. Yuridicheskii mir = Legal world, 2008, no. 3, pp. 23-28.

13. Gorokhovatskiy S.M. Constitutional and legal regulation of the process of formation and development of Federal relations in Russia after 2000. Aktual'nye problemy rossiiskogo prava = Actual problems of Russian law, 2015, no. 9, pp. 39-43.

14. Andreeva I.E. Formation and development of the institute of presidency in the Russian Federation. Armiya i obshchestvo = Army and society, 2013, no. 2, pp. 112-119.

15. Vetrenko I.A. Political technologies in modern political processes in Russia. Izvestia: Izvestiya Rossiiskogo gosudarstvennogo pedagogicheskogo universiteta im. A.I. Gertsena = Herzen University Journal of Humanities \& Sciences, 2009, no. 4, pp. 21-30.

16. Vetrenko I. A. New forms of populism in the modern world, in: Development policy, state and world order: materials of the all-Russian Congress of political scientists. Moscow, MSU Publ., 2018. P. 109-111.

\section{ИНФОРМАЦИЯ ОБ АВТОРЕ}

Ветренко Инна Александровна - доктор политических наук, профессор, заведующая кафедрой социальных технологий

Северо-Западный институт управления Российской академии народного хозяйства и государственной службы при Президенте Российской Федерации 199178, Россия, г. Санкт-Петербург, Средний пр. B.O., 57/43 e-mail: Vetrenko-IA@ranepa.ru

ORCID: 0000-0001-5212-4580

SPIN-код: 6566-4687; AuthorID: 287914

\section{БИБЛИОГРАФИЧЕСКОЕ ОПИСАНИЕ СТАТЬИ}

Ветренко И.А. Начало масштабной политической реформы в России: новый поворот в 2020 г. / И.А. Ветренко // Правоприменение. - 2020. - Т. 4, № 1. - C. 14-20. - DOI: 10.24147/2542-1514.2020. 4(1).14-20.

\section{INFORMATION ABOUT AUTHOR}

Inna A. Vetrenko - Doctor of Political Science, Professor; Head, Department of Social Technologies North-west institute of management of Russian Presidential Academy of National Economy and Public Administration (RANEPA)

57/43, Srednii pr. V.O., St. Petersburg, 199178, Russia e-mail: Vetrenko-IA@ranepa.ru

ORCID: 0000-0001-5212-4580

RSCI SPIN-code: 6566-4687; AuthorID: 287914

\section{BIBLIOGRAPHIC DESCRIPTION}

Vetrenko I.A. The beginning of a large-scale political reform in Russia: a new turn in 2020. Pravoprimenenie = Law Enforcement Review, 2020, vol. 4, no. 1, pp. 14-20. DOI: 10.24147/2542-1514.2020.4(1).1420. (In Russ.). 